\title{
Representações da fome: carestia e racialização na obra Pedaços da fome, de Carolina Maria de Jesus
}

\author{
[ Displays of hunger: scarcity and racialization in Carolina \\ Maria de Jesus' novel "Pedaços da fome"
}

\section{Fernando Cauduro Pureza ${ }^{\mathrm{I}}$}

\begin{abstract}
RESUMO - Neste ensaio, pretende-se problematizar as formas pelas quais a chamada "carestia de vida" era analisada na sociologia e na estatística das décadas de I950 e I960, contrastando-as com as representações formuladas por Carolina Maria de Jesus no romance Pedaços da fome. Entendendo a obra a partir de seu contexto de produção, cremos ser possível analisá-la também a partir da elaboração de uma crítica a um pensamento social que apagava as discussões raciais sobre a pobreza. Assim, a protagonista do romance, Maria Clara, seria uma chave de leitura formulada pela própria autora para compreender a fome e a miséria na São Paulo da época. • PALAVRAS-CHAVE - Carestia; Carolina Maria de Jesus; racializa-
\end{abstract}

\begin{abstract}
ção. · ABSTRACT · In this essay, we intend to question the ways in which the so-called "life scarcity" was analyzed in sociology and statistics in the I950s and I960s, contrasting them with the representations made by Carolina Maria de Jesus in her novel Pedaços da fome. Understanding this work from its production context, we believe it is possible to analyze it also from the elaboration of a criticism against a social theory, which erased racial discussions about poverty. Therefore, the leading character of the novel, Maria Clara, would be a key for this reading, created by the author as a way to understand hunger and poverty in São Paulo in those times. - KEYWORDS - Scarcity; Carolina Maria de Jesus; racialization.
\end{abstract}

Recebido em 8 de março de 2017

Aprovado em 29 de março de $20 \mathrm{I} 7$

PUREZA, Fernando Cauduro. Representações da fome: carestia e racialização na obra Pedaços da fome, de Carolina Maria de Jesus. Revista do Instituto de Estudos Brasileiros, Brasil, n. 66, p. 52-68, abr. 2017.

DOI: http://dx.doi.org/Io.II606/issn.23I6-90IX.voi66p52-68

I Universidade Federal do Rio Grande do Sul (UFRGS, Porto Alegre, RS, Brasil). 


\section{A FOME E A AUTORA}

Recentemente a canção brasileira passou a se debruçar sobre a figura da mãe solteira negra e sua batalha pela sobrevivência. Emicida, com "Levanta e anda" (20I3), e Racionais MC's, com “Negro drama” (2002), cada um à sua maneira, construíram essas personagens a partir das próprias experiências com as suas mães. Nesse aspecto, a figura de Carolina Maria de Jesus pode fornecer um interessante adendo para pensarmos essa imagem, pois tensiona tal questão pela perspectiva dessa mãe. Se nas duas canções acima temos a voz dos filhos homens como destaque, ao olharmos para a literatura produzida pela autora, veremos a força de uma narradora negra e mãe, capaz de descrever a fome e a lida cotidiana às quais está sujeita junto aos seus filhos. Ao analisar Quarto de despejo, por exemplo, a obra mais famosa da autora, há certamente uma visão bem menos idealizada da sua condição materna, que descreve com bastante realismo a luta pela sobrevivência em meio à selva de concreto.

Este artigo, contudo, pretende olhar para outra obra da autora, que certamente teve menor impacto em termos de crítica e, consequentemente, menor alcance se comparado com Quarto de despejo. Trata-se do romance publicado em I963 Pedaços da fome, que, ao contrário dos demais, tem uma narrativa mais tradicional, de caráter ficcional, com narrador um em terceira pessoa, cuja história gira em torno de Maria Clara, uma jovem filha de coronel, que, por amor, acaba sendo enganada pelo marido e é obrigada a morar em Guarulhos, num cortiço. O livro, segundo José Carlos Gomes Silva, tratava de "situações reais das quais [a autora] fora testemunha antes de mudar-se para a favela, em I948" e retomava, de forma alegórica, as "condições opressivas do trabalho doméstico que [Carolina Maria de Jesus] vivenciara entre 
I937-I948”2. Em outras palavras, tensionando memória e narrativa, a autora abarca uma experiência social que entrecruza diferentes temporalidades - e que, numa acepção mais generalista, pode-se dizer que compreende o período de I937 a I963 se for aceita a consideração de Silva.

Todavia, para além das experiências e memórias sobrepostas na narrativa, interessa-nos precisamente olhar para as representações da fome e da escassez descritas na vida de Maria Clara. A fome é um elemento crucial que ajuda não apenas a construir a personagem, mas a tensionar elementos da vivência cotidiana dos pobres da cidade de São Paulo. Como destaca Fernanda Rodrigues de Miranda, "a escassez material e a falta de cidadania” são pontos de relevo na estrutura literária da autora e, sendo assim, cidade e escassez caminham juntas na narrativa ${ }^{3}$. Em outras palavras, é possível afirmar que na estrutura da obra a fome aparece como uma espécie de artifício dotado de duplicidade: por um lado, ela se propõe a ser um fantasma que circunda as relações sociais dos personagens, mas, por outro lado, ela é uma construção literária que por vezes mascara outras relações sociais - a dizer, mais especificamente, a questão racial, que seria tão central na obra de Carolina Maria de Jesus.

Convém ressaltar que este não é um trabalho de crítica literária per se e sim um trabalho de historiador que, ao deparar-se com o objeto literário, procura analisá-lo a partir dos indícios apontados para a construção de um "estatuto de verdade". A tendência da literatura de Carolina Maria de Jesus em construir uma espécie de realismo do qual ela seria a intérprete acaba entrecruzando até mesmo sua obra romanesca ${ }^{4}$ e, em última instância, permite uma análise sobre as tensões entre real e ficcional que são construídas ao longo do romance, entrecortadas por uma temporalidade específica - por mais que ela seja bastante opaca ao longo do romance. Como afirma a historiadora Natalie Zemon Davis, não se trata de auferir uma distância preexistente entre o "narrado" e o "real", mas sim de observar escolhas de detalhes, linguagem e ordem na apresentação de um texto que procure se constituir se não como verdadeiro, ao menos como realista ${ }^{5}$. Assim, nas tensões de um contexto de produção da obra e de uma intérprete que cria uma série de artifícios para construir seu romance, pode-se entender a obra como um importante objeto de pesquisa, capaz de ser entendido não apenas pelo seu contexto de produção marcado pela miséria, como também pela possibilidade de ela própria constituir o contexto

2 SILVA, José Carlos Gomes. História de vida, produção literária e trajetórias urbanas da escritora negra Carolina Maria de Jesus. In: REUNIÃO BRASILEIRA DE ANTROPOLOGIA, 26., "Desigualdade na diversidade”, I 4 de junho, 2008. Porto Seguro. Anais... Porto Seguro, 2008, p. 22. Disponível em: 〈http://www.abant.org.br/ conteudo/ANAIS/CD_Virtual_26_RBA/grupos_de_trabalho/trabalhos/GT\%2007/jose\%20silva.pdf $>$. Acesso em: 29 mar. 2017.

3 MIRANDA, Fernanda Rodrigues de. Os caminhos literários de Carolina Maria de Jesus: experiência marginal e construção estética. Dissertação (Mestrado em Letras). Departamento de Letras Clássicas e Vernáculas, Faculdade de Filosofia, Letras e Ciências Humanas, Universidade de São Paulo, 20I3, p. 48.

4 VOGT, Carlos. Trabalho, pobreza e trabalho intelectual (O Quarto de despejo de Carolina Maria de Jesus). In: SCHWARZ, Roberto. Os pobres na literatura brasileira. São Paulo: Brasiliense, I983, p. 209

5 DAVIS, Natalie Zemon. Histórias de perdão e seus narradores na França do século XVI. São Paulo: Companhia das Letras, 200I, p. I6-I7. 
de fome e miséria que nos é apresentado - e no caso de Carolina Maria de Jesus, de uma forma bastante original.

\section{A FOME COMO DADO SÓcIO-HISTÓRICO}

Em outubro de I95I, movido pelo peso que o tema da "carestia de vida" tinha conquistado na campanha presidencial, Getúlio Vargas reuniu o economista Guerreiro Ramos e o médico Josué de Castro para construírem a Comissão Nacional do Bem-Estar Social (CNBES). O objetivo da comissão seria constituir estudos sobre "o padrão de consumo das famílias de trabalhadores em algumas capitais do país, numa primeira sondagem, de modo a fornecer subsídios para a revisão da política salarial". Sendo assim, para a realização do estudo inicial, Josué de Castro propôs que quatro capitais diferentes fossem analisadas: Porto Alegre, São Paulo, Fortaleza e Recife. Dos primeiros levantamentos feitos, logo em seguida os pesquisadores da CNBES confirmaram os dados acerca do custo de vida, demonstrando que, na cidade de São Paulo, o índice de participação dos gastos com alimentação era de 4I,I2\% do total das despesas das famílias operárias, um valor alto, mas inferior ao das capitais da Região Nordeste. Em média, a família típica de operários paulistanos era composta de 4,05 membros, que consumiam mensalmente 5,84 kg de carne e 22,55 litros de leite ${ }^{7}$. A obsessão estatística de economistas, médicos, sociólogos e demógrafos da época, que permitia que quantificassem aproximadamente todo o consumo dos trabalhadores de qualquer cidade do Brasil - e, sendo São Paulo uma das principais capitais -, ganhou destaque na produção estatística da época como uma forma de quantificar o problema do "custo de vida".

De fato, o levantamento da CNBES inventariou 77 itens diferentes de consumo alimentar para não apenas poder calcular o custo de vida, mas também para saber o quanto de cada um deles era consumido. Foi um momento auge da produção de estudos e estatísticas no Brasil - ainda que, como destaca o historiador Sydenham Lourenço, elas tenham sido pouco eficientes na elaboração de políticas públicas apesar do tamanho do aparelho burocrático à disposição de comissões como a $\mathrm{CNBES}^{8}$. Em última instância, tais pesquisas ajudaram a construir uma visão sobre o problema da "carestia de vida", que, apesar de todas as pretensões cientificistas, era, ainda assim, uma visão parcial, um fragmento de uma realidade social complexa e que afligia milhões de brasileiros.

Nesse caso, olhar para a literatura de Carolina Maria de Jesus, uma mulher negra e favelada, significa em última instância olhar para a forma como uma autora

6 LINHARES, Maria Yedda Leite; SILVA, Francisco Carlos Teixeira da. História política do abastecimento (I9I8-I974). Brasília: Binagri, I979, p. I44.

7 JOCHMANN, João. Padrões de alimentação dos industriários no Brasil. Revista Brasileira de Municípios. Rio de Janeiro, out.-dez. I955, p. 30 I.

8 LOURENÇO NETO, Sydenham. Modernização, crise e protesto popular: a questão do abastecimento nos anos 50. In: SIMPÓSIO NACIONAL DE HISTÓRIA - ANPUH: 50 anos, 26. Anais... São Paulo, Universidade de São Paulo, I7 a 22 de julho de 20II, p. 4-5. 
consegue transformar em narrativa literária suas experiências de pobreza e miséria sem, muito provavelmente, estar ciente de todo o aparato estatístico do estado que procurava mensurar os problemas do chamado "custo de vida". Nesse aspecto, todavia, Pedaços da fome, por ser sua primeira obra romanesca, acabou permitindo que a autora construísse uma imagem menos presa nas suas experiências "tal como aconteceram" e mais livre em termos de linguagem - em especial, se compararmos com suas obras anteriores, cujos caráter de diário (Quarto de despejo) e registro memorialístico (Casa de alvenaria) eram predominantes - e que, convém ressaltar, foram alvo da interferência direta do jornalista Audálio Dantas ${ }^{9}$ no processo de editoração.

O romance de I963, por sua vez, focalizava as desventuras de Maria Clara, menina rica do interior que acaba indo morar na cidade de São Paulo, sendo obrigada a encarar uma vida de pobreza ao lado de seu marido, Paulo Lemes, um personagem que encarna a figura de um sujeito avesso ao trabalho. Nesse caso, discutir a pobreza em I963 era, invariavelmente, falar dos males do "custo de vida", e a autora não se furta a essa questão - porém, ao mesmo tempo que busca estabelecer um cruzamento entre suas experiências e memórias na obra ficcional, abre-se a possibilidade de pensarmos o período entre I937 e I963 como uma espécie de continuum de "fome" e "carestia", problemas que persistiam ao longo do processo de modernização brasileira.

De fato, um dos "ganchos narrativos" para apresentar a personagem de Maria Clara é a sua relação com a sopa. Quando rica, a personagem era apresentada como alguém que não gostava de sopa e se recusava a tomá-la, no que o narrador completava: "Havia muitas coisas para comer, a mesa era farta e variada"тo. Porém, ao ir morar no cortiço e vendo-se diante de uma vida de pobreza, ficando por vezes sem comer, a protagonista acaba tendo um fortuito encontro com sua vizinha, dona Maura, que lhe dá um prato de sopa em troca de utilizar a máquina de costura recém-comprada por Maria Clara. Naquele momento, a personagem enxugou uma lágrima lembrando-se de sua pirraça juvenil para, logo em seguida, afirmar que "recebia a sopa como dádiva do céu", comendo tudo, "com tanto prazer como se fosse

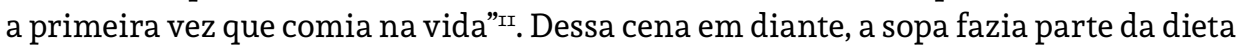
alimentar da protagonista, embora não sem haver alguns maldizeres ao longo do romance. No final do romance, é a sopa que vai permitir o reencontro com o seu pai.

A atenção para a sopa, contudo, não é gratuita. Feita com ossos e carnes de inferior qualidade, era um alimento providencial, mas nem sempre supria as calorias necessárias. O problema é que para além do debate mais técnico - que certamente não estava no horizonte do narrador -, há o problema da qualidade dos ingredientes. Em Quarto de despejo, Carolina Maria de Jesus relata o momento em que ganhou metade de uma cabeça de porco, quando ela e os filhos comeram a carne e ela acabou guardando os ossos para ferver depois e "fazer um caldo" com batatas - complementando a cena com um breve comentário no qual afirmava que os seus

9 JESUS, Carolina Maria de. Quarto de despejo. São Paulo: Ática e Francisco Alves, I960, p. II.

Io Idem. Pedaços da fome. São Paulo: Áquila, I963, p. 27.

II Ibidem., p. 86. 
filhos, quando com fome, "não são exigentes no paladar"ז2. Em Diário de Bitita, último livro de Carolina Maria de Jesus, com forte tom memorialístico, ela recordava que quando jovem conseguia "carne de cabeça" no frigorífico, uma "carne insípida", que "não tem sabor e nem cozinha"13. Em última instância, a referência da sopa dialogava precisamente com o alimentar-se com menos qualidade - se não em termos de saúde, em termos daquilo que Marshall Sahlins chamaria de uma espécie de tabu alimentar constituído socialmente sobre o que é aceitável, ou não, na dieta de determinada cultura $^{\mathrm{I}}{ }^{4}$. Nesse aspecto, a obra de Carolina ajuda a ampliar um ponto cego na análise das pesquisas da CNBES - as carnes, tais como apresentadas nas pesquisas, não eram distinguidas em cortes e, portanto, era difícil definir aspectos qualitativos sobre o que se comia (e quando se comia).

Há algo de curioso na narrativa que talvez seja importante destacar, que é justamente o ato de inventariar itens alimentícios, algo tão semelhante ao que faziam os estatísticos da época e que surgia de forma distorcida nas obras de Carolina Maria de Jesus. Em Pedaços da fome, pão, leite, café, manteiga, açúcar, queijo, frutas, verduras, ossos, miúdos, peixes, pirão, sanduíches, arroz, feijão e carne de frango surgem ao longo da narrativa, alguns com maior ou menor ênfase, alguns preparados e outros não. Mas, ao invés de serem um inventário de quantificação específica por meio do qual se poderia entender a evolução dos preços, o que o romance explicita é justamente a importância da alimentação na hora de constituir a fome. Há, sem dúvida, um paradoxo no fato de que abordar a comida seja justamente uma das formas mais explícitas de tratar da fome, - um recurso muito comum em Quarto de despejo, cujo volume de itens era ainda maior.

Essa abundância gera um dos poucos momentos em que Maria Clara sente algum tipo de satisfação na sua vida de pobreza, especialmente quando o marido consegue ganhar "uns trocados" e compra alguns produtos para alimentar sua família. Ele, que passara por toda a trama sendo considerado uma pessoa avessa ao trabalho, quando foi para a favela viu-se na condição de catador de latas. Com o que arrecadou, conseguiu comprar pão, leite, café, açúcar e queijo, enquanto Maria Clara chegava da feira com as crianças após ter coletado frutas e verduras, além de alguns ossos para fazer sopa - novamente ela. Nessa feita, Maria Clara afirmava que era "a primeira vez" que o marido trabalhara, para logo em seguida deliciar-se com um pedaço de queijo ("como se estivesse comendo pela primeira vez", como explica o narrador) ${ }^{\text {I5 }}$.

A satisfação, todavia, é singular, pois o tratamento para com a comida é constantemente marcado pelo receio em relação à falta de qualidade. Porém, os critérios que definiam a qualidade mostravam-se subjetivos: quando se viu na condição de empregada doméstica sem salário (uma menção muito próxima à vida de doméstica da própria Carolina Maria de Jesus), Maria Clara se sentiu na obrigação de comer apenas comida requentada. Com as preocupações da pobreza, o

I2 Idem. Quarto de despejo, op. cit., p. 93.

I3 Idem. Diário de Bitita. Rio de Janeiro: Nova Fronteira, I986, p. 96.

I4 SAHLINS, Marshall. La pensée bourgeoise: a sociedade ocidental enquanto cultura. In: Cultura e razão

prática. Rio de Janeiro: Jorge Zahar, 2003, p. I70-I76.

I5 JESUS, Carolina Maria de. Pedaços da fome, op. cit., p. I96. 
leite artificial era lamentado como o único substituto possível para alimentar seus filhos. A prática de coletar os restos das feiras livres no chão acabava fazendo com que ela e as crianças comessem frutas, legumes e verduras que estavam apodrecendo, o que por sua vez causava doenças. Contrastes didáticos sobre o valor da comida nas expressões das classes populares, que discutiam o que era comer com qualidade a partir não apenas da higiene, mas também do sabor e do preparo dos alimentos.

Disso se depreende que inventariar os alimentos e prepará-los adequadamente era uma forma de demarcar que a fome não se dava somente pelo não comer, mas também pelo não comer de acordo com uma qualidade e uma diversidade mínimas estabelecidas - o que evidencia muito mais um padrão moral compartilhado socialmente do que propriamente um gosto arbitrário. Em última instância, apresentar a comida ao mesmo tempo que se enfatiza a qualidade é um elemento crucial para que o narrador demonstre como é a fome de Maria Clara. Além de ter de violar os padrões do que é certo ou não comer para sobreviver, ela não tem nem mesmo a possibilidade da mesa farta. Nesse aspecto, a cena do queijo é uma das raras passagens em que a protagonista consegue encontrar algum alento.

A importância da fartura, mesmo que momentânea, não pode ser subestimada. Em Quarto de despejo, Carolina Maria de Jesus constantemente trazia a importância de não apenas comer, mas de ter refeições fartas. Em determinado momento, a narradora escrevera no diário: "Fui fazendo o jantar. Arroz, feijão, pimentão e chouriço e mandioca frita. Quando a Vera viu tanta coisa disse: hoje é festa de negro!" ${ }^{16}$. Comer bem, com refeições fartas, para quem constantemente vivia assombrado pelo fato de "pular refeições", era um grande evento social na unidade familiar. Era isso que poderia dar algum alento à perturbada alma de Maria Clara. Mas o termo "festa de negro" revela mais do que fartura na escrita da autora.

\section{Maria Clara e a difícil tarefa de construção da "Fome branca”}

Em abril de I964, pouco tempo depois da publicação de Pedaços da fome, o sociólogo Florestan Fernandes publicou sua tese de livre-docência na USP, A integração do negro na sociedade de classes. Na obra, Florestan Fernandes procurou discutir aquilo que chamava de "anomia" no "meio negro", partindo de uma concepção históricosociológica que concebia que a escravidão havia sido uma experiência tão desastrosa que, em última instância, estaria no bojo da explicação da falta de organização das comunidades negras no cenário pós-abolição. Trata-se de uma obra que busca tematizar a difícil integração dos negros na sociedade de classes brasileira, no que São Paulo seria seu exemplo mais distinto. Para o autor, os "negros e mulatos ficaram à margem ou se viram excluídos da prosperidade geral”, o que explicaria a dificuldade de se organizarem sob a bandeira de determinada classe social - no caso, o operariado urbano ${ }^{17}$.

I6 Idem. Quarto de despejo, p. 43.

I7 FERNANDES, Florestan. A integração do negro na sociedade de classes. Volume I: Ensaio de interpretação sociológica. Rio de Janeiro: Globo, 2008, p. I20. 
É tentador, a partir desse quadro, lançar o mesmo olhar sociológico de Florestan Fernandes para Carolina Maria de Jesus, ela também uma mulher negra e vivendo a "exclusão da prosperidade geral" - e que, para completar, ainda vivia na cidade de São Paulo, o mesmo cenário urbano da pesquisa de Florestan. Todavia, é possível tensionar a leitura sociológica apresentada pelo próprio fato de que a autora, ao invés de estar presa a um estado anômico e apático, revela-se como escritora, capaz de ficcionalizar a própria realidade. Em outras palavras, sua escrita e sua capacidade de articulação eram, inegavelmente, formas específicas de produção e organização de si e do mundo ao seu redor. Como avalia Carlos Vogt, a escritura de Carolina Maria de Jesus era uma forma de experimentação social nova, que rompia o cerco "da economia de sobrevivência que tranca a sua vida ao dia a dia do dinheiro-coisa"18.

Nesse ponto, a obra acaba se colocando como um interessante contraponto à concepção sociológica defendida por Florestan Fernandes e pela escola uspiana dos anos I960. Ora, boa parte da coleta de materiais da pesquisa dos sociólogos se deu nos espaços negros da cidade de São Paulo, dos quais possivelmente a favela do Canindé, onde residia Carolina Maria de Jesus, seria um. A autora, por sua vez, escreve Quarto de despejo e Pedaços da fome tendo como palco a capital paulista. A correlação especial entre sociologia e literatura parece destacar uma série de paralelismos, mas, justamente por poder falar deles enquanto "nativa", Carolina desloca e tensiona a tese de "anomia do meio negro" 1 .

Desse tensionamento, retoma-se a figura de Maria Clara, a protagonista do romance. Se não há precisão cronológica do presente narrativo de Pedaços da fome, pode-se manter a estimativa de que ele se dá numa constante entre I937 e I963, como dito anteriormente. Nesse meio-tempo, passam-se sete anos desde a fuga de Maria Clara para São Paulo até seu reencontro com o pai - um tempo ainda entrecortado pelo nascimento de seis filhos. Seu espaço de trânsito urbano é relativamente marcado, indo do interior até a capital, passando por um cortiço em Guarulhos, a casa de dona Raquel no Jardim Europa e uma favela sem identificação precisa. Mas, de tudo o que poderia ser dito, talvez um dos traços mais sui generis de Maria Clara - que, em última instância, também diz respeito ao narrador e aos demais personagens - seja a total ausência de reflexões sobre raça ao longo do processo. A

I8 VOGT, Carlos, op. cit., p. 2Io.

I9 O historiador Álvaro Nascimento destaca que o mérito da obra de Florestan e seus discípulos na sociologia uspiana é inegável e que foi responsável pela crítica em larga escala feita ao mito da democracia racial. Todavia, como destaca o autor, tais pesquisas "também revelam os perigos das explicações causais contidas nestes importantes trabalhos da década de I960", tais como a ideia de que "havia uma "desorganização social dos negros' cuja causa fora a 'herança deformadora da escravidão', que os mutilara intelectual e moralmente, dificultando a inserção desse grupo na nova conjuntura econômica trazida pelo capitalismo”. A crítica é pertinente justamente porque ressalta como a obra de Florestan forneceu uma narrativa sócio-histórica capaz de apagar a agência de homens e mulheres negras no contexto de pós-abolição. Para mais, ver: NASCIMENTO, Álvaro Pereira de. Caminhos de negros: vida, trabalho e desenvolvimento urbano no pós-abolição (Nova Iguaçu, I880-I980). In: Anais do XXVI SIMPÓSIO NACIONAL DE HISTÓRIA - ANPUH: 50 anos, 26., Anais.... São Paulo, Universidade de São Paulo, I7 a 22 julho de 20 II. 
única personagem que, de fato, possui alguma designação racial é a protagonista, identificada como "branca".

Na verdade, a posição social de Maria Clara enquanto "filha de coronel" é revelada ao leitor logo nas primeiras páginas, sendo marcada pelo fato de ser bonita, uma das melhores alunas da escola, exímia pianista, ingênua e branca. De fato, há certo estereótipo sobre a personagem, que parece ser a protagonista típica das novelas de amor. Desconhecia a vida social, já que não saía do interior e, quando saiu, ficou evidente que suas interações com os trabalhadores a serviço de seu pai eram típicas de alguém cujas ordens eram cumpridas de pronto, em um contexto que os desumanizava no próprio romance, nem sequer tendo direito a serem nomeados por ela ou pelo narrador. Nesse contexto de desumanização, é curioso perceber que Maria Clara chega a ter crises de consciência posteriormente sobre a forma com que tratava os mais pobres, mas não há em nenhum momento qualquer reflexão sobre a cor dos trabalhadores. Em última análise, poderia se afirmar que a protagonista criada por Carolina Maria de Jesus carregaria consigo um dos privilégios mais típicos dos processos da branquidade, no caso, o de apagar as tensões raciais ao redor dela.

Não é apenas a protagonista que assume esse papel, pois o narrador da obra também não toca na questão da raça, não identificando a cor dos demais personagens; somente Maria Clara é que ganha a dimensão exata, pois ela é uma mulher branca. Há tamanha invisibilidade racial que seria possível perguntar se o narrador da obra Pedaços da fome não seria ele também um sujeito envolto nos privilégios da branquidade, incapaz de refletir sobre raça e processos de racialização. Como destaca Liv Sovik,

[...] a hipervalorização silenciosa do branco consegue fazer sentido, não porque as classes hegemônicas são uniformemente brancas, mas porque nos permite reconfirmar que estamos diante do poder (ou da "beleza”), na forma que assumiu durante o processo histórico que começou com a colonização europeia”º.

Em outras palavras, a construção de uma personagem branca indicava o corolário de uma noção de beleza. Silenciosa e cruel o suficiente para aparecer aqui de forma sutil: valorizando a cor de Maria Clara para, com isso, ao mesmo tempo, negar a dimensão racial dos demais personagens. Como destaca Sovik, "quanto mais silenciada a branquidade, mais difícil combater fora do terreno em que ela reina". Assim, Maria Clara e o narrador compartilham desse pacto de silêncio sobre raça ao longo do romance.

Contudo, há um paradoxo curioso ao analisar a obra. Ao tratar da fome como mote central para o comportamento dos personagens, Carolina Maria de Jesus utiliza as próprias experiências para construir a protagonista Maria Clara. Mas a mediação da linguagem ficcional permitiu que a autora criasse uma jovem branca para com isso poder discutir aspectos específicos de uma fome como fenômeno ligado à pobreza, mas não necessariamente ligado à raça. Em certo momento, Carolina, negra, e Maria

20 SOVIK, Liv. Aqui ninguém é branco: hegemonia branca e media no Brasil. In: WARE, Vron (Org.). Branquidade: identidade branca e multiculturalismo. São Paulo: Garamond, 2004, p. $37 \mathrm{I}$. 
Clara, branca, poderiam encontrar-se nos mesmos lugares sociais, tendo que catar comida nos restos das feiras-livres. Segundo José Carlos Gomes da Silva, esse seria um recurso narrativo da própria autora para evitar o caráter de "depoimento" em sua obra literária e assim poder desconectar sua experiência imediata em relação ao leitor ${ }^{21}$. Dessa forma, Maria Clara poderia identificar-se com os pobres, mas não necessariamente compartilharia de todas as suas experiências, como fica evidente na seguinte passagem:

Maria Clara tinha receio de passar fome. Ficava horrorizada quando via as mulheres pobres vagando pelas ruas pedindo esmolas. Revoltava-se pensando:

- Será que os nossos políticos não têm vergonha de ver tantos pobres circulando pelas ruas? [...] Quando eu era rica não me preocupava muito com os pobres, mas agora estou nesse núcleo. Se os ricos conhecessem a vida sacrificada que os pobres levam, haviam de obrigar seus filhos a estudar e aprender uma profissão $0^{22}$.

A pobreza de Maria Clara, coletivizada no repetitivo termo "pobres" e na expressão "nesse núcleo", denotava que, mesmo branca, ela se considerava parte do grupo social no qual se identificava. Mas esse sentimento é tensionado ao longo do romance, denotando muito mais estranhamento do que sentimento de identidade compartilhada. Não faltavam vezes em que a personagem era humilhada pelos demais vizinhos em Guarulhos e na favela, sendo tratada como alguém que não pertencia àquela realidade. Em determinado episódio, Maria Clara estragou as roupas de uma vizinha e foi por ela espancada, causando furor no cortiço em que morava. A protagonista acabou sendo presa e, da história, carregou a humilhação de receber a alcunha de "pianista", pois era considerada uma mulher que sabia usar as mãos somente para se maquiar e tocar piano, sem aptidão para lavar roupas. Ainda assim, apesar de toda a humilhação, de sentir-se uma outsider diante da pobreza, ela ainda podia reivindicar para si a condição de "pobre" e, com isso, construir uma noção de que a fome atingia todos os pobres por igual, independente da raça ou do gênero - ou até mesmo de suas vidas pregressas. Esse fator gera a estranheza sobre o apagamento racial que a personagem realiza, ainda mais num contexto em "que $89 \%$ das mulheres de cor empregadas fora das atividades primárias e industriais" concentravam-se nos serviços pessoais, "principalmente no emprego doméstico", como afirma Carlos Hasenbalg23.

Por outro lado, se Maria Clara apaga a questão racial, tal posição é traída justamente pelas metáforas que a personagem emprega ao lidar com sua condição de pobreza. Tais metáforas não falam explicitamente de raça, é bem verdade, mas destacam a escravidão como situação correlata - em verdade, Maria Clara sente-se escrava pela pobreza, condição pela qual culpa seu esposo, Paulo Lemes. Mas ela

2I SILVA, José Carlos Gomes, op. cit., p. 23.

22 JESUS, Carolina Maria de. Pedaços da fome, p. 154 .

23 HASENBALG, Carlos. Discriminação e desigualdades raciais no Brasil. Belo Horizonte: Editora da UFMG; Rio de Janeiro: Iuperj, 2005, p. I82. 
também é capaz de responsabilizar os ricos e entender que eles seriam causadores dessa nova forma de escravidão. Afirma a protagonista: "Eu não conhecia a mania dos ricos porque quando somos ricos não percebemos o quanto a nossa exigência escraviza uma pessoa. Mas eu também obriguei muitos pobres a curvar-se aos meus pés. [...] Quantos pobres hão de estar ressentidos comigo". Todavia, aquilo que parece ser uma tomada de consciência política transforma-se numa saída um tanto quanto insólita: "Se eu voltar a ser rica um dia, juro que hei de ser filantrópica. Eu nunca dei uma esmola a um pobre" 24 .

A saída filantrópica que Maria Clara constrói - e a qual talvez ela aplique no final do romance, dependendo da chave interpretativa com que ele for encarado - acaba tornando opaca uma transição pela qual a personagem passa. Se no início do romance ela não percebe o poder que possui sobre os trabalhadores de seu pai, que se rendiam aos seus caprichos, ao viver na pobreza ela passa a entender algo tão forte quanto o ressentimento. Mas, para além dessa conscientização, o que convém destacar aqui é justamente a ambiguidade da posição de Maria Clara: ao empregar a metáfora da escravidão, ela poderia aproximar a discussão sobre raça e traçar paralelos com sua caracterização sobre a insensibilidade dos ricos. Ser rico é, em última instância, ter exigências que "escravizam" os pobres. Ora, por que não ir mais adiante e destacar que a pobreza e a raça se entrecruzam diretamente? Todavia, a personagem não consegue ir adiante, pois a própria branquidade não daria conta de tamanho salto - caso fosse diferente, talvez Maria Clara pudesse deixar bem claro que ao falar dos ricos ainda falava de si, menina branca que, mesmo empobrecida, podia acionar o seu passado de fartura como uma espécie de distinção social. Todavia, para construir a ideia de que ela pertence ao grupo dos "pobres", é preciso diluir qualquer menção à raça e, assim, apagar os privilégios que assentaram sua existência até antes de ela conhecer Paulo Lemes.

É difícil estabelecer a posição social de Maria Clara como uma posição social privilegiada, principalmente considerando a pobreza que enfrenta ao longo do romance. Essa não é uma história somente sobre a pobreza, mas sim sobre a mobilidade social, por mais inverossímil que ela possa parecer. Por ter sido rica, a protagonista teve um passado de opulência, empobrecendo posteriormente para, em seguida, voltar a ter o mesmo estilo de vida que tinha antes. Nesse contexto, sua mobilidade social não parecia capaz de dialogar com nenhuma questão racial, e isso não se daria somente por um exercício estético por parte da autora. De fato, se olharmos para Quarto de despejo, é possível perceber que Carolina Maria de Jesus narra sua experiência utilizando-se justamente da chave interpretativa que aproxima a condição de riqueza à branquidade e que associa, por sua vez, sua pobreza com sua negritude. Nesse sentido, há uma interessante passagem na obra na qual Carolina vai até o rio buscar sacos de papel e descobre que eram sacos de arroz que estavam nos armazéns e tinham estragado. Ao escrever sobre a situação, Carolina afirma:

Fiquei horrorizada vendo o arroz podre. Contemplei as traças que circulavam, as baratas e os ratos que corriam de um lado para outro. Pensei: por que é que o homem 
branco é tão perverso assim? Ele tem dinheiro, compra e põe nos armazéns. Fica brincando com o povo igual gato com rato" 25 .

Maria Clara, por sua vez, nunca poderia ir tão longe em sua afirmação de pobreza. Culpava os ricos, é bem verdade, mas não responsabilizava os brancos. Sua fome era "descolorida" porque assim a branquidade permitiria. Ao mesmo tempo, ela emprega uma linguagem típica de quem conhecia a escravidão e poderia fazer aproximações metafóricas sobre ela - de certa forma, Maria Clara tenta, ao longo do romance, reivindicar que sua condição é a de uma "escrava". Mas o limite estrutural dessa reivindicação é o mesmo daquela afirmação na qual ela se considera uma dos "pobres": ela não poderia, em hipótese alguma, discutir raça - ou, de outra forma, toda sua identificação com os "pobres" seria colocada em xeque. Sua escravidão seria exclusivamente a da fome e a da pobreza e, nesse aspecto, é possível afirmar que essa metáfora era empregada por Carolina com relativa frequência em Quarto de despejo. Mas enquanto Carolina Maria de Jesus podia falar sobre a escravidão em paralelo com a questão racial, ressaltando sua negritude, esse artifício de linguagem não passava por Maria Clara. Afinal, seria realmente tão difícil que uma personagem como Maria Clara percebesse que sua condição social a afastava cada vez mais da "prosperidade geral", tal como afirmava Florestan Fernandes?

Para entender isso, é necessário destacar novamente a importância da fome no livro. Maria Clara não tem momentos de "festa de negro", pois sua branquidade criava outra dinâmica para sua relação com a pobreza, diferente até mesmo da que Carolina Maria de Jesus narrara em Quarto de despejo. É possível levantar, por sua vez, que essa ausência parece ter dois motivos: o primeiro, é claro, porque Maria Clara não era negra - e, até onde o narrador nos indica, ninguém mais seria em sua família. Isso, contudo, ajuda a entender também o alto grau de mobilidade social pelo qual Maria Clara passa no romance: de menina rica a mulher pobre, e de mulher pobre voltando a ser rica por uma espécie de encontro fortuito. Esse tipo de mobilidade social, por sua vez, não decorreu de uma espécie de luta pela sobrevivência, amparada na posição social da branquidade, mas sim do próprio fato de sua origem ter sido retomada num passe quase insuspeito de acaso. Se para uma mulher negra e pobre no Brasil a ascensão social era algo limitado, para Maria Clara era apenas uma memória a ser retomada - tão logo volta a ser rica, ela dá a volta por cima na favela e retorna, com seus seis filhos, para o interior de São Paulo, levando consigo a sua vizinha, dona Maura (que lhe serviria como uma espécie de "dama de companhia"). Em última instância, um dos grandes privilégios da figura de Maria Clara é justamente a facilidade em esquecer sua pobreza - algo semelhante ao que acontecera com a tia de Paulo Lemes, dona Raquel. Há, nas entrelinhas, um chamado sutil para que o leitor perceba que a ascensão social seria possível somente num meio em que a raça fosse irrelevante - e, nesse caso, estaria se reconstituindo silenciosamente o privilégio da branquidade.

O segundo motivo pelo qual Maria Clara não teria, ao longo do romance, uma "festa de negro" talvez seja ainda mais interessante para fins analíticos: a total

25 Idem. Quarto de despejo, op. cit., p. I30 (grifos nossos). 
ausência de abundância de alimentos em Pedaços da fome ajuda a elaborar a ideia de um consumo frugal e limitado de alimentos. Isso faz sentido se pensamos na pobreza e na miséria como dados absolutos, presos no linguajar estatístico da época, ou seja, de que havia um déficit de calorias conforme o custo de vida aumentava para as famílias mais pobres. Todavia, por mais objetivo que fosse esse dado, a literatura sociológica da época apontava para uma tensão dentro dessa noção de pobreza e escassez que era justamente a ideia de que a pobreza derivava não de um "racionamento alimentar", mas sim de uma condição em que se comia o máximo possível em determinado momento, pois, diante de uma insegurança estrutural, não se sabia quando se teria o que comer - algo que atingiria principalmente a população negra urbana. Numa passagem de Quarto de despejo, Carolina narra a seguinte cena:

Eu já fiz o almoço - hoje foi almoço. Tinha arroz, feijão e repolho e linguiça. Quando eu faço quatro pratos penso que sou alguém. Quando vejo meus filhos comendo arroz e feijão, o alimento que não está no alcance do favelado, fico sorrindo atoa [sic]. Como se eu estivesse assistindo [a] um espetáculo deslumbrante" ${ }^{\text {"26 }}$.

Essa relação entre um consumo ostensivo em situação de miséria não é propriamente uma novidade ligada a processos de racialização, embora talvez essa afirmativa precise ser ponderada diante de diferentes realidades sócio-históricas. A título de exemplo, valeria a pena retomar o seminal trabalho de E. P. Thompson sobre a formação da classe operária inglesa. Ao escrever sobre os trabalhadores sazonais ingleses do século XIX, o historiador britânico destacava que eles "não podiam planejar meticulosamente seus jantares durante os cinquenta e dois domingos do ano: ao contrário, gastavam seu dinheiro no período de emprego e consumiam o que pudessem durante o resto do ano" ${ }^{27}$. Em outras palavras, nas situações de escassez e insegurança estrutural movidas pela precariedade do trabalho (ou pela falta dele), a lógica que pautava a alimentação não era necessariamente a de um racionamento rigoroso e estrito, mas poderia estar balizada pela perspectiva de ter abundância pelo menos uma vez - pois, depois, sabe-se lá quando haveria um momento assim de novo. Dessa maneira, não seria natural que Maria Clara adquirisse o hábito de alimentar-se com fartura para depois racionar suas porções, tal como faziam outros pobres?

Nesse ponto, retomando a literatura sociológica da época e o termo "festa de negro”, presente em Quarto de despejo, há uma dimensão racial que não pode ser ignorada nesse consumo baseado na abundância. Ao analisar as dificuldades na integração dos negros na sociedade de classes de São Paulo, Florestan Fernandes destacou como uma das características da população negra de São Paulo aquilo que ele denominou como "nível de vida associável a uma ocupação conspícua e rendosa" ${ }^{28}$. Disso se depreendia um consumo extensivo (que Florestan observava principalmente a partir do vestuário), cuja ambição de "ter uma mesa farta 'todo

26 Ibidem, p. 44 .

27 THOMPSON, Edward Palmer. A formação da classe operária inglesa. Volume 2: A maldição de Adão. Rio de Janeiro: Paz e Terra, I988, p. I8I.

28 FERNANDES, Florestan, op. cit. p. I87. 
dia"”29 era algo irreprimível. Como afirma o autor, "quem 'tivesse com que', comia carne diariamente (se possível 'a fartar') e queria ver na mesa dois ou três pratos de 'mistura', condenando-se severamente os hábitos de moderação alimentar dos estrangeiros, que levavam a 'sacrificar o estômago' ou a tirar 'dinheiro da boca'”30. De fato, não faltam passagens em Quarto de despejo que corroboram parte dessa afirmação, destacando-se, por exemplo, o momento em que Carolina Maria de Jesus adquirira um porco para o consumo seu e de sua família e a importância da fartura de carne naqueles relatos. Essa fartura perduraria por alguns dias até que, novamente, a escassez se abatesse sobre o lar.

Se tal relação com a fome e a miséria era racializada dessa forma, seria perfeitamente possível entender o porquê de Maria Clara não viver suas "festas de negro”. Não havia nenhuma abundância, somente a falta de alimentos constante intercalada com a comida de baixa qualidade. Em última instância, poderia se dizer que a protagonista de Pedaços da fome estava passando pelos percalços comuns às populações urbanas mais pobres de São Paulo, mas a forma como ela lidava com essa condição era radicalmente diferente da de seus supostos pares. E, dada a forma pela qual o romance é conduzido, a única vizinha que auxilia Maria Clara com comida é dona Maura, que lhe oferece sopa. Se por acaso ocorriam "festas de negro", lautos e fartos banquetes, a protagonista nem mesmo era convidada por sua vizinhança, o que denotaria ainda mais a sua exclusão naquele meio de pobreza.

Em última instância, a literatura de Carolina Maria de Jesus permite tensionar algo que a sociologia e a estatística de sua época parecem ter considerado relativamente lateral: afinal, a fome e a miséria teriam uma cor específica? Existia uma forma tipicamente racializada de lidar com a chamada "carestia de vida"? Seria possível afirmar que o impacto do "custo de vida" teria desdobramentos raciais? De certa forma, sociólogos, nutricionistas, estatísticos, médicos e demógrafos da época pareciam cair na armadilha de Maria Clara e considerar que as questões sobre a "carestia de vida" não teriam especificidades raciais a serem consideradas.

\section{A armadilha de Maria Clara}

Parece temerário investigar a fome como fenômeno racializado no Brasil do século $\mathrm{XX}$, e qualquer conclusão que ateste isso talvez esteja sendo muito peremptória sem ao menos sustentar tal afirmação a partir de um estudo empírico de fôlego. Todavia, parte desse receio acaba advindo do fato de que os campos da sociologia, da estatística, da medicina nutricional e da demografia da época não constituíram como preocupação central os desdobramentos raciais dos problemas do chamado "custo de vida”, sendo que sua marcação era basicamente amparada em questões específicas de classe - especialmente quando sua análise ocorria no espaço urbano de capitais como São Paulo, Rio de Janeiro, Porto Alegre, entre outras. Dessa constatação, não implica que a chamada "carestia de vida" era um fenômeno exclusivamente racial,

29 Ibidem, p. I88.

30 Ibidem. 
mas que certamente as abordagens das décadas de I950 e I960 sobre o problema não se debruçaram sobre as consequências do alto custo de vida para as populações negras e pobres.

Nesse ponto, é possível compreender o romance de Carolina Maria de Jesus como uma espécie de "duplo" dessa perspectiva. Assim como toda a gama do pensamento "científico" que se debruçava sobre a carestia, Carolina resolve tirar de cena a questão racial de Pedaços da fome. O resultado, contudo, evidencia a ausência e ilustra uma característica típica da posição privilegiada que enxerga exclusivamente a questão da pobreza pelas lentes da classe, mas que não reflete sobre ela a partir da negritude. Maria Clara emerge como o outro lado de um pensamento social branco, incapaz de entender a pobreza pelo recorte racial - algo que a própria Carolina trazia em suas demais obras literárias. Nesse ponto, Maria Clara monta uma espécie de armadilha para o leitor, descrevendo a pobreza de um ponto de vista de alguém que já foi rico, mas que sempre foi branco. A invisibilidade dos processos de racialização é compartilhada também pelo narrador em terceira pessoa e, no final das contas, é possível passar por Pedaços da fome sem considerar que é uma obra sobre raça. Da mesma forma, é possível também analisar os dados estatísticos da CNBES e verificar que eles tampouco falam sobre raça. Maria Clara acaba, por sua vez, reverberando o tom oficial dos estudiosos sobre a pobreza no Brasil nas décadas de I950 e I960. Se a ela faltam as estatísticas, há a vivência - e ainda assim, ambos convergem no que diz respeito ao apagamento da questão racial.

Todavia, convém ressaltar que este trabalho é um início de conversa que partiu de uma pesquisa que se debruçou sobre os problemas sócio-históricos da chamada "carestia de vida" e procurou dialogar justamente com a obra de Carolina Maria de Jesus como quem olha para o relato de um "nativo". A surpresa, contudo, veio do fato de que o "nativo" que Carolina Maria de Jesus constrói no seu romance levanta mais questões sobre um objeto de pesquisa que parecia circunscrito somente à temática referente às classes sociais. Graças à armadilha de Maria Clara, foi possível levantar a possibilidade de que os efeitos do custo de vida tenham sido distintos não apenas conforme as classes sociais, como seria evidente, mas também conforme os processos de racialização. Em outras palavras, até que ponto a fome da criatura é a mesma fome de sua criadora?

Sem poder responder as perguntas aqui levantadas, cremos ser importante não deixar de lado a relevância da obra de Carolina Maria de Jesus como um objeto de análise específico para entender o Brasil urbano das décadas de I950 e I960. Por um lado, há o contexto de produção da obra, que está diretamente relacionado com a linguagem realista da autora - a preocupação com o "custo de vida" e a realidade do chamado subproletariado urbano, as condições de vida dos catadores e moradores de cortiços e favelas na cidade de São Paulo, a miséria e a fome de uma população que vivia à margem do processo de industrialização e modernização brasileira. Carolina Maria de Jesus escreveu a partir dessa realidade e, de certa forma, isso ajuda a constituir a força e a atualidade da sua produção literária. Por outro lado, cabe também analisar as formas pelas quais a linguagem da autora acaba construindo o próprio contexto - ou, nos dizeres de Mário Augusto Medeiros da Silva, como a autora 
acaba por "ficcionalizar seu cotidiano" ${ }^{31}$. Esse ato ficcional chega ao extremo na elaboração de uma personagem branca e rica que passa pelas agruras da fome, o que não era uma tentativa de evitar o caráter de depoimento em sua obra, nem tampouco uma orquestrada vingança. Era um exercício estético que buscava problematizar um aspecto da realidade da própria Carolina Maria de Jesus e tensioná-lo via uma difícil artimanha que é justamente a do apagamento racial, fugindo assim tanto da obsessão estatística quanto da narrativa sociológica da anomia.

Talvez não seja possível conceber ainda como a "carestia de vida" em São Paulo nos anos I950 e I960 seria ela também um processo de racialização, demarcando fronteiras entre o que seria uma "fome branca" e uma "fome negra". Mas esse nunca foi o objetivo da obra de Carolina Maria de Jesus. O que ela fez, contudo, foi brincar com a possibilidade aventada pela ciência da época de que a fome não tivesse uma barreira racial. Que o romance se demonstre inverossímil, mesmo que apartado por uma linguagem realista, exigiria que fosse feita reflexão semelhante sobre a produção científica relacionada ao "custo de vida". Em outras palavras, a armadilha de Maria Clara mostra justamente que a fome, enquanto dado sócio-histórico, está longe de ser uma medida universalmente quantificada. Especialmente no Brasil, onde, parafraseando Mano Brown, a figura da mulher negra, mãe solteira de "promissores vagabundos"32, daria um filme.

SOBRE O AUTOR

FERNANDO CAUDURO PUREZA é doutor em História pela Universidade Federal do Rio Grande do Sul (UFRGS) e autor de "Isso não vai mudar o preço do feijão": as disputas em torno da carestia em Porto Alegre (1945I964) (Editora Prisma, no prelo).

E-mail: fcpureza@gmail.com

\section{REFERÊNCIAS BIBLIOGRÁFICAS}

DAVIS, Natalie Zemon. Histórias de perdão e seus narradores na França do século XVI. São Paulo: Companhia das Letras, 200I.

3I SILVA, Mário Augusto Medeiros da. A descoberta do insólito: literatura negra e literatura periférica no Brasil (I960-2000). Rio de Janeiro: Aeroplano, 20I3, p. 372.

32 "[...] Daria um filme/ Uma negra/ E uma criança nos braços/ Solitária na floresta/ De concreto e aço/ [...] Família brasileira/ Dois contra o mundo/ Mãe solteira/ De um promissor/Vagabundo [...]”. RACIONAIS MC’S. “Negro drama”. In: . Nada como um dia após o outro. CD I - Chora agora. São Paulo: Cosa Nostra

Fonográfica/Zambia, 2002. 
FERNANDES, Florestan. A integração do negro na sociedade de classes. Volume I: Ensaio de interpretação sociológica. Rio de Janeiro: Globo, 2008.

HASENBALG, Carlos. Discriminação e desigualdades raciais no Brasil. Belo Horizonte: Editora UFMG; Rio de Janeiro: Iuperj, 2005.

JESUS, Carolina Maria de. Quarto de despejo. São Paulo: Ática e Francisco Alves, I96o. . Pedaços da fome. São Paulo: Áquila, I963.

. Diário de Bitita. Rio de Janeiro: Nova Fronteira, I986.

JOCHMANN, João. Padrões de alimentação dos industriários do Brasil. Revista Brasileira de Municípios. Rio de Janeiro, out.-dez. I955, p. 299-3I4.

LINHARES, Maria Yedda Leite; SILVA, Francisco Carlos Teixeira da. História política do abastecimento (I9I8-I974). Brasília: Binagri, I979.

LOURENÇO NETO, Sydenham. Modernização, crise e protesto popular: a questão do abastecimento nos anos 50. In: SIMPÓSIO NACIONAL DE HISTÓRIA - ANPUH, 26., 20II, São Paulo. Anais..., São Paulo: USP, I7-22 de julho de 20 II.

MIRANDA, Fernanda Rodrigues de. Os caminhos literários de Carolina Maria de Jesus: experiência marginal e construção estética. Dissertação (Mestrado em Letras). Programa de Pós-graduação em Estudos Comparados de Literaturas de Língua Portuguesa, Departamento de Letras Clássicas e Vernáculas, Faculdade de Filosofia, Letras e Ciências Humanas, Universidade de São Paulo, 2013.

NASCIMENTO, Álvaro Pereira de. Caminhos de negros: vida, trabalho e desenvolvimento urbano no pós-abolição (Nova Iguaçu, I880-I980). In: SIMPÓSIO NACIONAL DE HISTÓRIA - ANPUH, 26., 20II, São Paulo. Anais..., São Paulo: USP, I7-22 de julho de 20 II.

RACIONAIS MC’S. “Negro drama”. In:___. Nada como um dia a pós o outro. CD I -Chora gora. São Paulo: Cosa Nostra Fonográfica/Zambia, 2002.

SAHLINS, Marshall. La pensée bourgeoise: a sociedade ocidental enquanto cultura. In: . Cultura e razão prática. Rio de Janeiro: Jorge Zahar, 2003.

SILVA, José Carlos Gomes. História de vida, produção literária e trajetórias urbanas da escritora negra Carolina Maria de Jesus. In: REUNIÃO BRASILEIRA DE ANTROPOLOGIA, 26., "Desigualdade na diversidade”, I a 4 de junho, 2008. Porto Seguro. Anais... Porto Seguro, 2008, p. 22. Disponível em: <http://www.abant.org.br/conteudo/ANAIS/CD_Virtual_26_RBA/grupos_de_trabalho/trabalhos/ GT\%2007/jose\%20silva.pdf >. Acesso em: 29 mar. 2017.

SILVA, Mário Augusto Medeiros da. A descoberta do insólito: literatura negra e literatura periférica no Brasil (I960-2000). Rio de Janeiro: Aeroplano, 20I3.

SOVIK, Liv. Aqui ninguém é branco: hegemonia branca e media no Brasil. In: WARE, Vron (Org.). Branquidade: identidade branca e multiculturalismo. Tradução de Vera Ribeiro. São Paulo: Garamond, 2004.

THOMPSON, Edward Palmer. A formação da classe operária inglesa. Volume 2: A maldição de Adão. Rio de Janeiro: Paz e Terra, I988.

VOGT, Carlos. Trabalho, pobreza e trabalho intelectual (O Quarto de despejo de Carolina Maria de Jesus). In: SCHWARZ, Roberto. Os pobres na literatura brasileira. São Paulo, Brasiliense: I983. 